J. Dairy Sci. 92:3503-3509

doi:10.3168/jds.2008-1623

(C) American Dairy Science Association, 2009.

\title{
Quality assessments of waste milk at a calf ranch
}

\author{
D. A. Moore,$^{* 1}$ J. Taylor, $†$ M. L. Hartman, $\ddagger$ and W. M. Sischo* \\ ${ }^{*}$ College of Veterinary Medicine, Washington State University, Pullman 99164-6610 \\ †Westside Veterinary Services, Los Banos, CA 93635 \\ ‡California State University Fresno, College of Social Sciences, Fresno 93740
}

\section{ABSTRACT}

Nonsaleable whole milk from dairy farms is potentially an economical, nutritious source of feed for neonatal calves but it can have serious quality problems. Many calf-rearing operations that utilize this milk have no system in place to assess or manage quality problems other than pasteurization. The purpose of this investigation was to evaluate the quality of nonsaleable whole milk from dairy farms being used to feed neonatal calves using a set of standard milk quality monitors. In this study, nonsaleable whole milk samples from 12 dairies supplying both milk and calves to one calf ranch were collected and evaluated for total solids (TS) percentage, bacterial counts, coagulation with ethanol, somatic cell counts, and $\mathrm{pH}$. Milk quality was not uniform among the farms. Bacterial counts provided relatively little useful information to assess milk quality, because most samples (9/12) had very high bacteria counts. The most variable quality finding was TS percentage. Many samples were low in TS, contributing to a low TS percentage in pooled milk being fed to calves, which created a poor nutritional product delivered to them. Although there are advantages to feeding nonsaleable whole milk to preweaned calves, there can be significant disadvantages if the quality of the product is poor. Microbial quality is an important aspect of milk, but most of the samples were highly contaminated and the need for pasteurization was assumed. Simpler and more immediate monitoring methods such as milk $\mathrm{pH}$, the alcohol test, and TS could be used at the ranch to make decisions on whether to use the milk. On the study ranch, a program to evaluate the TS of nonsaleable whole milk was implemented and a chart to add solids was devised for the producer so that the neonatal calves would not be underfed nutrients. Implementing these measures will help improve the health and growth of young calves.

Key words: calf, herd health, waste milk

Received August 12, 2008.

Accepted February 23, 2009.

${ }^{1}$ Corresponding author: damoore@vetmed.wsu.edu

\section{INTRODUCTION}

Although whole milk is generally considered the best feed for young calves, the cost of utilizing fluid milk originally intended for human consumption as calf feed is often cost prohibitive. Thus, milk replacers were developed as a blend of less expensive ingredients to provide nutrients to calves. However, past evaluation of milk replacers revealed variation in the digestibility of those ingredients (Medina et al., 1983), which encouraged some dairy producers and calf ranch operators to switch to utilizing dairy nonsaleable milk as an inexpensive alternative (Godden et al., 2005). Nonsaleable milk includes postparturient milk, which is harvested after the first-milking colostrum for the first days of a cow's lactation, as well as discarded milk from treated cows.

It is common for calf-ranch operators who are contracted to raise heifers from multiple sources to purchase bull calves and nonsaleable milk from their clients. This milk will then be used to feed the contract calves. The waste milk from these different sources is usually pooled before being fed. The major concern in using this milk has been excessive bacterial contamination. Although bacteria can be shed directly into the milk by the source cow (a cow with mastitis), contamination is more often the result of inadequate sanitation during harvesting, handling, and storage of the milk. This contamination can be exacerbated through temperature abuse associated with the lack of refrigeration during transportation and storage. As a result, producers and calf-ranch operators have built or purchased pasteurizers to reduce the bacterial load in the milk and minimize the occurrence of pathogens such as Salmonella or Mycoplasma (Selim and Cullor, 1997; Butler et al., 2000). The economic benefit of feeding pasteurized nonsaleable waste milk compared with milk replacer has been demonstrated. Calves fed pasteurized milk had improved weight gain and reduced morbidity and mortality (Jamaluddin et al., 1996; Godden et al., 2005).

Although managing and minimizing bacterial contamination of the milk fed to calves should be a primary focus of a calf-feeding program, other milk quality 
measures should be considered. The objectives of this investigation were to assess rapid, simple methods commonly used to evaluate milk quality to identify possible quality problems in nonsaleable milk at a calf ranch and provide protocols for ameliorating detected quality problems in waste milk.

\section{MATERIALS AND METHODS}

\section{Study Farm}

The calf ranch in this investigation reared approximately 3,500 preweaned, dairy-source heifer and bull calves in individual hutches until $60 \mathrm{~d}$ of age when they were weaned. Calves less than 3 wk of age were fed a $22 \%$ CP milk replacer with $20 \%$ fat (on a DM basis). At 1 wk of age until weaning, calves were supplemented with ad libitum calf starter grain $(19.4 \%$ CP, 0.56 Mcal of $\mathrm{NE}_{\mathrm{G}}, 14.1 \% \mathrm{NDF}$, and $8.9 \%$ ash on a DM basis). Beginning at $3 \mathrm{wk}$ of age, calves were fed pooled, pasteurized nonsaleable milk purchased from contract dairies. This milk was collected by drivers when picking up calves from client dairy farms. Before accepting the milk, drivers would smell the milk and refuse to take it if it smelled "off." If deemed acceptable, the milk would be pumped into 1,514-L tanks on the livestock-hauling truck. At the calf ranch, the herd manager subjectively assessed the quality of the milk (before pasteurization) for odor, color, and consistency to determine whether to feed it or not. Once accepted at the ranch, the milk was pumped from the truck to a stainless steel bulk tank. Because of the lack of transport and bulk tank refrigeration, the milk was immediately pasteurized in 757-L batches using a continuous flow pasteurizer (Good Nature Pasteurizer, Goodnature Products Inc., Orchard Park, NY) that was set to reach $77^{\circ} \mathrm{C}$. The pasteurized milk was then fed to calves on the ranch in 1.89-L bottles. If there was insufficient nonsaleable milk or if the pasteurizer failed, these older calves were supplemented with a $20 \% \mathrm{CP}$ and $20 \%$ crude fat milk replacer. The ranch sporadically evaluated postpasteurization microbial milk quality by plating pasteurized milk on blood agar and looking for bacterial growth.

At a monthly herd health visit, the records indicated that mortality among hutch calves was elevated over previous months (reaching approximately 10\%), and the herd manager reported that calves over 3 wk of age appeared thin. This latter observation was validated during the herd visit through observation. At that time, the primary concern was over the quality of the feed given to the calves. Because there was a monitoring program for postpasteurization milk quality, it was felt that other milk quality aspects might be deficient.

\section{Sample Collection and Analysis}

To assess the quality of the nonsaleable milk objectively, route drivers were asked to collect milk samples from 12 dairies in $10-\mathrm{mL}$ sterile containers before loading the milk into the transport tanks. In addition, pooled pre- and postpasteurization samples of this milk were collected at the calf ranch.

Milk TS were measured using a Brix refractometer (Reichert Inc., Depew, NY). The method is temperatureindependent and capable of measuring TS in a variety of fluid substrates. It has been used to measure TS in milk ranging between 5 and 15\% (normal values for whole milk average 13\%; Foley and Otterby, 1978). As recommended by the manufacturer, a standard curve was created to convert the refractometer values to actual TS percentages. Briefly, 78 milk samples were evaluated for TS percentage. Seventy-eight dairy bulk tank samples were randomly selected from one creamery for testing. Water was added to 4 of the milk samples to provide a wide range of TS percentage values. All samples were evaluated at a certified dairy analytical laboratory (Sierra Dairy Labs, Tulare, CA) using a mid-infrared method as described (Wehr and Frank, 2004) using a spectrophotometer (Bentley 150, Bentley Instruments, Chaska, MN). Percentage fat and SNF were summed to estimate TS percentage. Refractometer readings (Brix) were obtained for each of the standard samples, and the refractometer values were regressed against infrared estimates to obtain a standard curve equation (Figure 1). The refractometer results from the nonsaleable milk samples were converted to estimated TS percentage values using the calculated standard curve equation.

The $\mathrm{pH}$ of the milk samples was determined using a calibrated hand-held pH meter (Twin pH B-212, Horiba Instruments Ltd., Northampton, UK). Normal pH for milk is 6.5 to 6.7 (Okigbo et al., 1985). Ethanol coagulation tests were conducted on all samples (Sommers and Binney, 1922). One milliliter of nonsaleable milk was added to an equal amount of 70 to $75 \%$ ethanol. Coagulation was detected as fine particles of curd visible in the milk.

The SCC (cells $/ \mathrm{mL}$ ) were determined for each sample using a portable, automated cell counter (DeLaval cell counter, DeLaval Inc., Kansas City, MO), and each nonsaleable milk sample and pooled pre- and postpasteurized milk samples from the calf ranch were evaluated for presence and quantity of bacteria. From each sample, a $10-\mu \mathrm{L}$ aliquot of agitated milk was plated to each of washed bovine blood agar (Hardy Diagnostics, Santa Maria, CA), MacConkey agar (Hardy Diagnostics), and PPLO agar (Hardy Diagnostics). In addition, a cotton swab $(\approx 100 \mu \mathrm{L})$ immersed in the milk samples 
was placed in enriched Mycoplasma broth, incubated for $24 \mathrm{~h}$ at $37^{\circ} \mathrm{C}$, and plated on PPLO agar plates. The blood agar and MacConkey plates were incubated overnight at $37^{\circ} \mathrm{C}$. The PPLO agar plates were read at 3 and $7 \mathrm{~d}$ (National Mastitis Council, 1999). The samples were also evaluated for the presence of Salmonella enterica. A cotton swab was immersed in each of the milk samples and transferred to tetrathionate broth (Becton, Dickinson and Co., Sparks, MD). The tetrathionate broth was incubated overnight at $37^{\circ} \mathrm{C}$, plated to xylose lysine deoxycholate and brilliant green agar plates (Hardy Diagnostics), and incubated overnight at $37^{\circ} \mathrm{C}$. Salmonella were identified based on typical colony morphology and biochemical reactions (Berge et al., 2007).

\section{RESULTS}

Nonsaleable milk quality varied from sample to sample (Table 1). Based on the refractometer results,
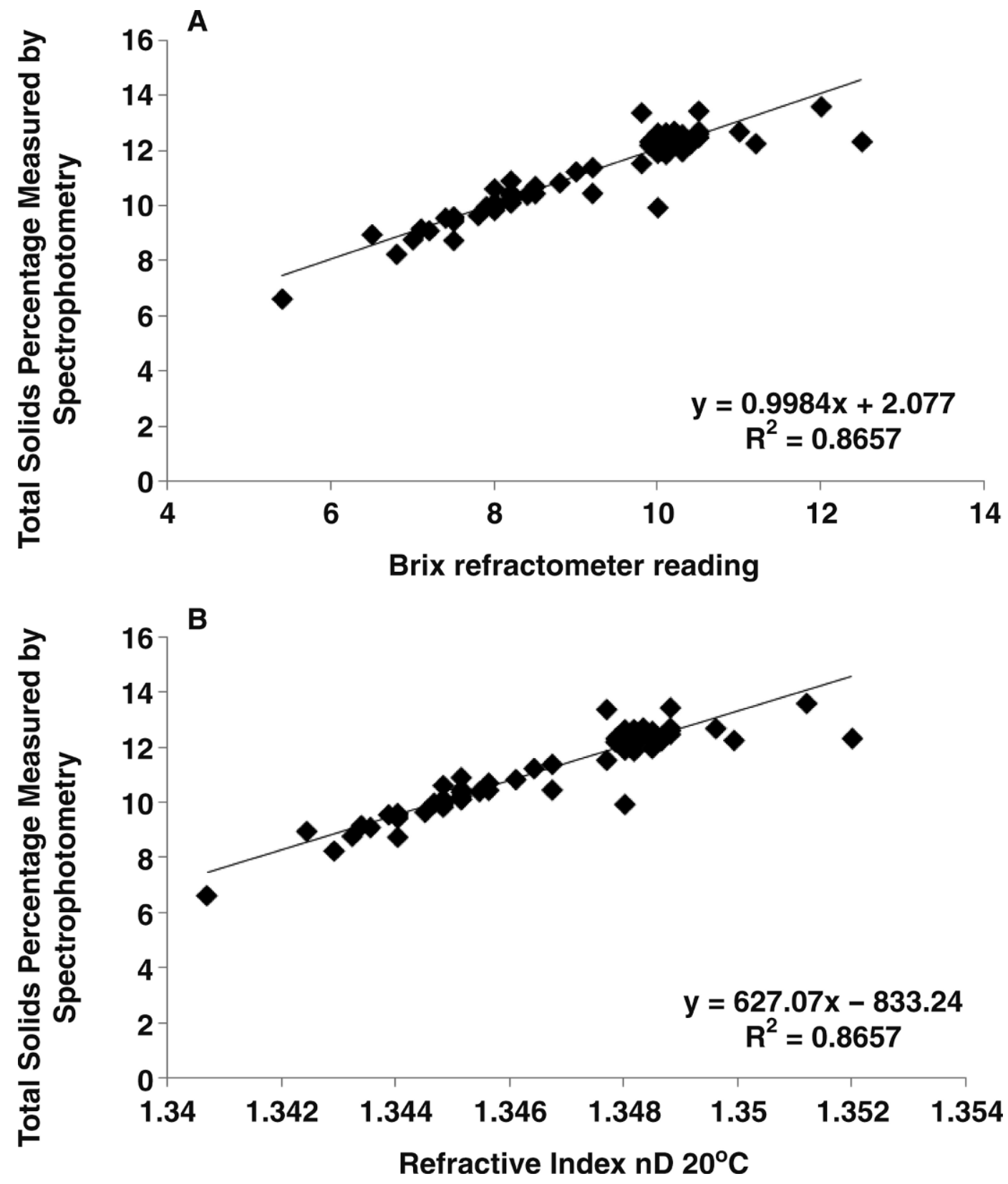

Figure 1. Regression of Brix refractometer readings (A) and refractive index (B) for total milk solids percentage based on infrared estimates from 78 dairy bulk tank samples $(P=0.003)$. 


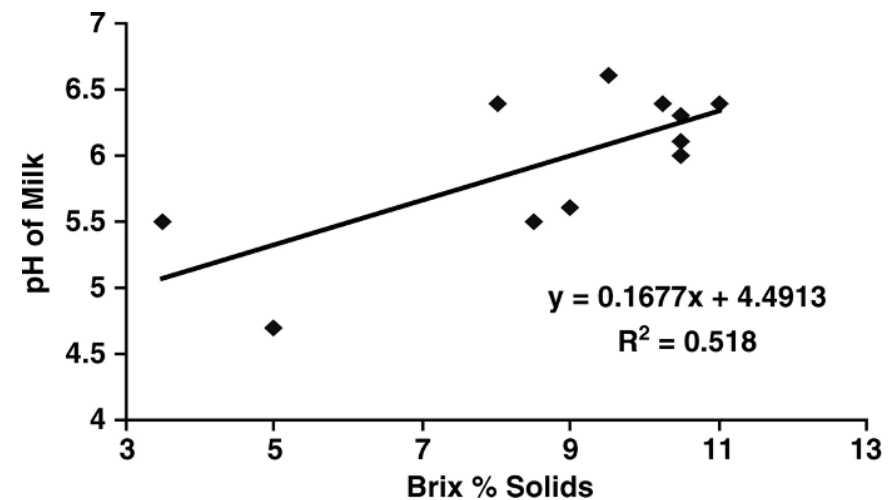

Figure 2. Regression of Brix refractometer readings for TS (\%) and $\mathrm{pH}$ of dairy waste milk samples $(P=0.01)$.

the TS percentages from the nonsaleable milk samples were lower than expected. The TS estimates from the dairy and calf ranch samples ranged from 5.1 to $13.5 \%$. Six of the 12 dairy samples had TS estimates $<12.0 \%$. The pooled sample from the calf-ranch bulk tank (from all 12 dairies) was $11.0 \% \mathrm{TS}$, lower than the expected 12.5 to $13 \%$ for whole milk.

Most of the nonsaleable milk samples (8/12) had low $\mathrm{pH}$ values and a positive ethanol coagulation test result indicating milk spoilage. Total solids percentage measured by the refractometer was moderately but significantly correlated with the $\mathrm{pH}$ of the sample $\left(\mathrm{R}^{2}=\right.$ $0.518 ; P=0.01$; Figure 2). All samples, including the pooled sample, had large numbers of mixed growth and coliform bacterial colonies per $10 \mu \mathrm{L}$. Pasteurization of the pooled milk resulted in a much lower bacterial count (100 colonies per $10 \mu \mathrm{L})$. Neither Mycoplasma spp. nor Salmonella spp were detected in any of the samples.

\section{DISCUSSION}

Pasteurization of nonsaleable is recommended to reduce bacterial counts and improve the quality of milk fed to neonatal calves (Selim and Cullor, 1997; Reynolds, 2002; Stabel et al., 2004; Godden et al., 2005). However, identification of other quality problems associated with feeding nonsaleable milk, particularly with regard to the nutrient value and spoilage of milk before pasteurization, has not been evaluated. This investigation highlights the fact that bacterial contamination is not the only important quality measure for nonsaleable milk feeding.

The most significant nutritional problem detected was low TS percentage in the milk samples. A likely cause of low TS in waste milk is the inadvertent addition of water to the product because of postmilking clean-up procedures in the hospital parlor. To help

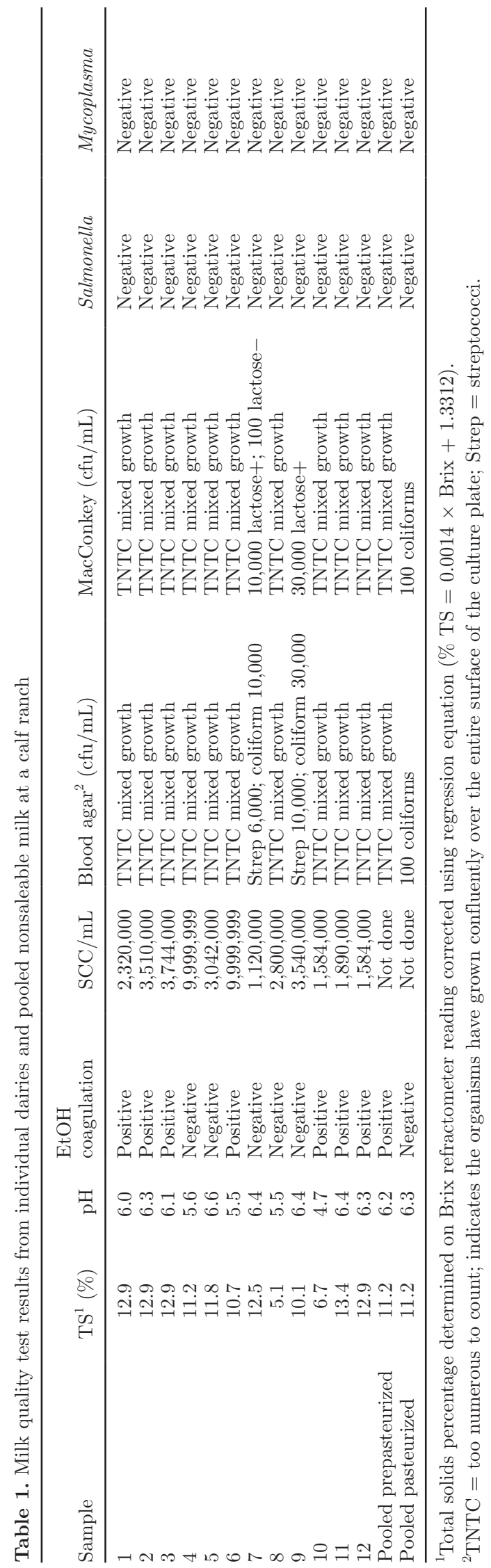


Table 2. Example protocol developed to feed $13 \%$ TS to neonatal calves based on low refractometer readings for TS of pooled waste milk

\begin{tabular}{|c|c|c|c|c|c|c|}
\hline Milk (L) & TS of milk ${ }^{1}(\%)$ & TS needed (\%) & $\begin{array}{l}\text { Amount of milk } \\
\text { replacer to add }(\mathrm{kg})\end{array}$ & $\begin{array}{l}\text { Bags of milk } \\
\text { replacer }^{2}(\mathrm{n})\end{array}$ & Total $\operatorname{cost}^{3}(\$)$ & Cost/calf $(\$)$ \\
\hline 757 & 2 & 13 & 98 & 4.30 & 193.50 & 0.48 \\
\hline 757 & 3 & 13 & 89 & 3.92 & 176.40 & 0.44 \\
\hline 757 & 5 & 13 & 71 & 3.12 & 140.40 & 0.35 \\
\hline 757 & 6 & 13 & 62 & 2.74 & 123.30 & 0.31 \\
\hline 757 & 7 & 13 & 53 & 2.35 & 105.60 & 0.26 \\
\hline 757 & 10 & 13 & 27 & 1.18 & 53.10 & 0.13 \\
\hline 757 & 11 & 13 & 18 & 0.78 & 35.10 & 0.09 \\
\hline
\end{tabular}

${ }^{1}$ From regression estimate of actual TS percentage based on Brix refractometer reading compared with infrared analysis.

${ }^{2}$ Milk replacer: $20 \%$ protein, $20 \%$ fat milk replacer powder; $22.7 \mathrm{~kg}$.

${ }^{3}$ Estimated cost of milk replacer powder $=\$ 45.00$ per $22.7-\mathrm{kg}$ bag.

improve the nutrient density of waste milk, we recommended that the ranch manager evaluate the pooled milk sample using a refractometer before feeding and add milk replacer powder as needed to achieve $13 \%$ TS before feeding the milk. We developed a chart to guide the feeders (Table 2).

The refractometer actually measures the refractive index $(\mathbf{R I})$, which for milk at $20^{\circ} \mathrm{C}$ is 1.3440 to 1.3485 , and can be used to estimate percentage TS (Fox and McSweeney, 1998). Some refractometers are designed to provide results as RI, whereas some of the hand-held models provide percentage of solids (Bradley, 2003). The RI varies with the concentration of the compound, the temperature, and the wavelength of light. Some refractometers are temperature independent. The Brix refractometer can be purchased as temperature-independent and used to measure dissolved solids and the percentage of solids in milk; Brix is a unit equal to the grams of sucrose/100 g of sample. Regardless of the refractometer used, the RI of milk is considered difficult to estimate because of the presence of fat globules and casein micelles (Fox and McSweeney, 1998). However, if a thin layer of milk is used, analysis can be relatively accurate. When using the refractometer, it is essential that the refractometer prism is cleaned of any remaining milk residue between samples.

Standard curves have been developed for RI and TS for reconstituted nonfat dry milk (Radewonuk et al., 1983). Our trend line for RI versus TS $[R I=0.0014(\mathrm{TS})$ $\left.+1.3312 ; \mathrm{R}^{2}=0.8657\right)$ is similar to that reported by Radewonuk et al. [1983; RI $=0.00165(\mathrm{TS})+1.33195)$. The RI was estimated based on our Brix readings from standards provided by the International Commission for Uniform Methods of Sugar Analysis and regressed on the TS estimate from the spectrophotometer (Figure 1; International Commission for Uniform Methods of Sugar Analysis, 1979). In addition to RI, specific gravity is another way of measuring milk density and is about 1.0330 for normal Holstein and Jersey milk (Fox and McSweeney, 1998). Specific gravity may be better used to estimate SNF (Fox and McSweeney, 1998). Any of these methods can be used to identify diluted milk. Freezing-point depression measurement of milk samples is used by the dairy industry to detect illegal addition of water to bulk tank milk and is not sensitive to fat content, but this cryoscopy method is not as portable as a refractometer (Chen et al., 1996) and cannot be used to estimate TS to make feeding decisions.

The primary (assumed) benefit of feeding nonsaleable milk is that the calf will consume more calories compared with feeding standard milk replacers (Godden et al., 2005). A calf drinking $3.78 \mathrm{~L}$ of milk daily will consume approximately $2.97 \mathrm{Mcal}$ of ME if the nonsaleable milk contains $12.5 \%$ TS (NRC, 2001). A calf consuming the same volume of a $20 \%$ protein $/ 20 \%$ fat milk replacer would only consume $2.47 \mathrm{Mcal}$ (if the mixture were fed at a rate of $2.2 \mathrm{~kg} /$ calf per day). As demonstrated by our investigation, the potential for dilution of nonsaleable milk exists, and assumptions about the nutrient density of this milk need to be reconsidered. As an alternative strategy to adding milk replacer to increase the solids percentage of the nonsaleable milk, larger volumes of milk could be fed. However, this may not fit into the processes established on the calf-rearing facility if the facility uses a 2-L bottle-feeding program. This could easily be accomplished, however, with bucket feeding.

Most of the milk samples tested were positive on the ethanol test and had low $\mathrm{pH}$. The ethanol test to monitor for milk spoilage is not commonly used in developed countries but is still used at points along the milk-handling chain in developing countries with smallholding dairy producers and a lack of refrigeration (Bonfoh et al., 2003). The milk composition parameters being evaluated in the ethanol test include casein percentage (and nonfat solids), which is lower in ethanol test-positive samples, and $\mathrm{Cl}, \mathrm{Na}$, and $\mathrm{K}$, which are 
higher in ethanol test-positive samples (Chavez et al., 2004).

Only one sample had a $\mathrm{pH}$ within normal range (6.5-6.7). Measuring $\mathrm{pH}$ is a simple way to identify spoilage, but the $\mathrm{pH}$ of milk will decrease initially and then increase depending on the stage of spoilage, time, temperature, and the bacteria present. Microbial spoilage of food can affect not only color and odor, which may affect intake, but can also affect the nutrient content. In our study, $\mathrm{pH}$ was significantly correlated with the percentage of TS: the lower the $\mathrm{pH}$, the lower the TS measurement. Although intentionally acidified milk (with added organic acids) has been fed to calves successfully and resulted in fewer calves with scours (Jaster et al., 1990; Yanar et al., 2006), feeding spontaneously acidified (i.e., spoiled) milk may not have the same effects. Although measurement of SCC is not an on-farm test, SCC in the waste milk samples indicated that mastitic cows were contributing to the waste milk pool. High SCC are associated with low total milk solids and protein and may have contributed to the low TS seen in the samples (Munro et al., 1984; Politis and Ng-Kwai-Hang, 1988). In milk intended for human consumption, the Pasteurized Milk Ordinance (US Department of Health and Human Services, 2003) has set a limit of 750,000 cells $/ \mathrm{mL}$, a limit that was exceeded by all the dairy waste milk samples in this study.

The gold standard for measuring milk quality is the bacterial count. All but 2 samples in this investigation had levels of bacteria classified as "too numerous to count." Although pasteurization reduced bacteria to a low level, there is concern that preformed toxins or by-products from bacterial death could cause harm to neonates. High coliform levels could lead to high endotoxin levels in the milk. Under normal conditions, the intestinal wall acts as a barrier to passage of endotoxin from the intestine into the bloodstream, but disruption of the barrier could lead to systemic endotoxemia. An investigation of enteral endotoxins given to rat pups resulted in translocation of endotoxin across the gut, resulting in endotoxemia and bacteremia, likely because of the immature neonatal immune system (Townsend et al., 2007). To our knowledge, no work in enteral administration of endotoxin to calves has been reported.

Other bacteria, in addition to coliforms, can be found in waste milk including staphylococci (such as Staphylococcus aureus), Streptococcus spp., and Bacillus spp. (Selim and Cullor, 1997). Staphylococcal enterotoxin (an exotoxin from Staph. aureus) is heat stable and can induce platelet dysfunction (Tran et al., 2006) and immunosuppression through effects on bovine $\mathrm{T}$ cells (Seo et al., 2007). It is a cause of foodborne disease in people, affecting the very young and the very old more seriously (Balaban and Rasooly, 2000). Bacillus spp. have the ability to form spores that can survive pasteurization (Vissers et al., 2007) and can produce a heat-stable toxin, cereulide (Taylor et al., 2005). The cereulide toxin has been associated with the inhibition of human natural killer cell activity (Paananen et al., 2002) but has not been studied in calves.

Although pasteurizing waste milk will reduce or eliminate pathogens, lower bacterial counts of waste milk presented to the pasteurizer should be a goal, and contamination of milk and temperature abuse at each step from harvest to pasteurization should be reduced. Periodic culturing of milk from dairies that ship waste milk to calf ranches could be used to educate producers about the importance of quality milk being fed to their heifers raised on the calf ranch. Culturing postpasteurized milk regularly can help identify pasteurizer problems early.

\section{CONCLUSIONS}

The quality of waste milk can be highly variable. The most important finding of this investigation was the low TS percentage of the dairy waste milk being fed to neonatal calves and the correlation of low $\mathrm{pH}$, indicating spoilage, to the low TS percentage. Dairy advisors can assist producers and calf-ranch managers who feed waste milk to develop ways to monitor quality, provide feedback to dairies supplying waste milk, and develop ways to ensure that young calves are fed consistent, quality nutrients. In particular, protocols that assess and remediate low TS fed to calves in liquid feeding programs are critical to provide adequate nutrition, and protocols to reduce contamination and spoilage will promote calf health.

\section{REFERENCES}

Balaban, N., and A. Rasooly. 2000. Staphylococcal enterotoxins. Int. J. Food Microbiol. 61:1-10.

Berge, A. C., S. Champagne, R. Finger, and W. M. Sischo. 2007. The use of bulk tank milk samples to monitor trends in antimicrobial resistance on dairy farms. Foodborne Pathog. Dis. 4:397-407.

Bonfoh, B., A. Wasem, A. N. Traore, A. Fane, H. Spillmann, C. F. Simbe, I. O. Alfaroukh, J. Nicolet, Z. Farah, and J. Zinsstag. 2003. Microbiological quality of cows' milk taken at different intervals from the udder to the selling point in Bamako (Mali). Food Contr. 14:495-500.

Bradley, R. L. 2003. Moisture and total solids analysis. Pages 95-96 in Food Analysis. S. S. Nielsen, ed. Birkhauser, Basel, Switzerland.

Butler, J. A., S. A. Sickles, C. J. Johanns, and R. F. Rosenbusch. 2000. Pasteurization of discard mycoplasma mastitic milk used to feed calves: Thermal effects on various mycoplasma. J. Dairy Sci. $83: 2285-2288$.

Chavez, M. S., L. M. Negri, M. A. Taverna, and A. Cuatrin. 2004. Bovine milk composition parameters affecting the ethanol stability. J. Dairy Res. 71:201-206.

Chen, P., X. D. Chen, and K. W. Free. 1996. Measurement data interpretation of the freezing depression point depression of milks. J. Food Eng. 30:239-253. 
Foley, J. A., and D. E. Otterby. 1978. Availability, storage, treatment, composition, and feeding value of surplus colostrum: A review. J. Dairy Sci. 61:1033-1060

Fox, P. F., and P. L. H. McSweeney. 1998. Physical properties of milk Pages 437-461 in Dairy Chemistry and Biochemistry. Blackie Academic \& Professional, New York, NY.

Godden, S. M., J. P. Fetrow, J. M. Feirtag, L. R. Green, and S. J. Wells. 2005. Economic analysis of feeding pasteurized nonsaleable milk versus conventional milk replacer to dairy calves. J. Am. Vet. Med. Assoc. 226:1547-1554

International Commission for Uniform Methods of Sugar Analysis. 1979 Sugar Analysis: Official and Tentative Methods Recommended by the International Commission for Uniform Methods of Sugar Analysis. F. Schneider, ed. ICUMSA, Peterborough, UK.

Jamaluddin, A. A., T. E. Carpenter, D. W. Hird, and M. C. Thurmond. 1996. Economics of feeding pasteurized colostrum and pasteurized waste milk to dairy calves. J. Am. Vet. Med. Assoc. 209:751756.

Jaster, E. H., G. C. McCoy, T. Tomkins, and C. L. Davis. 1990. Feeding acidified or sweet milk replacer to dairy calves. J. Dairy Sci. 73:3563-3566.

Medina, M., L. W. Johnson, A. P. Knight, J. D. Olson, and L. D. Lewis. 1983. Evaluation of milk replacers for dairy calves. Compend. Contin. Educ. Pract. Vet. 5:S148-S152.

Munro, G. L., P. A. Grieve, and B. J. Kitchen. 1984. Effects of mastitis on milk yield, milk composition, processing properties and yield and quality of milk products. Aust. J. Dairy Technol. 33:7-16.

National Mastitis Council. 1999. Laboratory Handbook on Bovine Mastitis. National Mastitis Council Inc., Madison, WI.

National Research Council. 2001. Nutrient requirements of the young calf. Pages 214-233 in Nutrient Requirements of Dairy Cattle. National Academy Press, Washington, DC.

Okigbo, L. M., G. H. Richardson, R. J. Brown, and C. A. Ernstrom. 1985. Coagulation properties of abnormal and normal milk from individual cow quarters. J. Dairy Sci. 68:1893-1896.

Paananen, A., R. Mikkola, T. Sareneva, S. Matikainen, M. Hess, M. Andersson, I. Julkunen, M. S. Salkinoja-Salonen, and T. Timonen. 2002. Inhibition of human natural killer cell activity by cereulide, an emetic toxin from Bacillus cereus. Clin. Exp. Immunol 129:420-428

Politis, I., and K. F. Ng-Kwai-Hang. 1988. Effects of somatic cell count and milk composition on cheese composition and cheese making efficiency. J. Dairy Sci. 71:1711-1719.

Radewonuk, E. R., E. O. Strolle, and J. C. Craig. 1983. Freezing points of skim milk concentrates. J. Dairy Sci. 66:2061-2069.
Reynolds, J. P. 2002. Pasteurizing waste milk on dairies and calf ranches. Pages 179-181 in Proceedings of the WildWest Veterinary Conference, Reno, NV.

Selim, S. A., and J. S. Cullor. 1997. Number of viable bacteria and presumptive antibiotic residues in milk fed to calves on commercial dairies. J. Am. Vet. Med. Assoc. 211:1029-1035.

Seo, K. S. S. U. Lee, Y. H. Park, W. C. Davis, L. K. Fox, and G. A. Bohach. 2007. Long-term staphylococcal enterotoxin C1 exposure induces soluble-mediated immunosuppression by bovine CD4+ and CD8+ T cells. Infect. Immun. 75:260-269.

Sommers, H. H., and T. H. Binney. 1922. A study of the factors that influence the coagulation of milk in the alcohol test. J. Dairy Sci. 6:176-197.

Stabel, J. R., S. Hurd, L. Calvente, and R. F. Rosenbusch. 2004. Destruction of Mycobacterium paratuberculosis, Salmonella spp. and Mycoplasma spp. in raw milk by a commercial on-farm hightemperature, short-time pasteurizer. J. Dairy Sci. 87:2177-2183.

Taylor, J. M. A. Sutherland, K. E. Aidoo, and N. A. Logan. 2005. Heat-stable toxin production by strains of Bacillus cereus, Bacillus firmus, Bacillus megaterium, Bacillus simplex and Bacillus licheniformis. FEMS Microbiol. Lett. 242:313-317.

Townsend, S., J. C. Barron, C. Loc-Carrillo, and S. Forsythe. 2007. The presence of endotoxin in powdered infant formula and the influence of endotoxin and Enterobacter sakazakii on bacterial translocation in the infant rat. Food Microbiol. 21:67-74.

Tran, U., T. Boyle, J. W. Shupp, R. Hammamieh, and M. Jett. 2006. Staphylococcal enterotoxin B initiates protein kinase $\mathrm{C}$ translocation and eicosanoid metabolism while inhibiting thrombin-induced aggregation in human platelets. Mol. Cell. Biochem. 288:171-178.

US Department of Health and Human Services. 2003. Grade A Pasteurized Milk Ordinance. USPHS:FDA, ed. Public Health Service, Food and Drug Administration, Milk Safety Branch, College Park, MD.

Vissers, M. M., M. C. TeGiffel, F. Driehuis, P. DeJong, and J. M. Lankveld. 2007. Minimizing the level of Bacillus cereus spores in farm tank milk. J. Dairy Sci. 90:3286-3293.

Wehr, H. M., and J. H. Frank. 2004. Pages 460-479 in Standard Methods for the Examination of Dairy Products. 17th ed. Am. Public Health Assoc., Washington, DC

Yanar, M., O. Guler, B. Bayram, and J. Metin. 2006. Effects of feeding acidified milk replacer on the growth, health and behavioral characteristics of Holstein Friesian calves. Turk. J. Vet. Anim. Sci. 30:235-241. 